\title{
Intra- vs Intermolecular Photoinduced Electron Transfer Reactions of a Macrocyclic Donor-Acceptor Dyad
}

\author{
Evan G. Moore, ${ }^{*}, \uparrow$ Paul V. Bernhardt, ${ }^{\dagger}$ Alexandre Fürstenberg, ${ }^{\ddagger}$ Mark J. Riley, ${ }^{\dagger}$ and \\ Eric Vauthey* \\ Department of Chemistry, School of Molecular and Microbial Sciences, University of Queensland, \\ Brisbane 4072, Australia, and Physical Chemistry Department, Sciences II, University of Geneva, 30, \\ Quai Ernest-Ansermet, 1211 Geneva 4, Switzerland
}

Received: August 22, 2005

\begin{abstract}
The synthesis, structural characterization, and photophysical behavior of a 14-membered tetraazamacrocycle with pendant 4-dimethylaminobenzyl (DMAB) and 9-anthracenylmethyl groups is reported $\left(\mathrm{L}^{3}\right.$, 6- $((9$ anthracenylmethyl)amino)-trans-6,13-dimethyl-13-((4-dimethylaminobenzyl)amino)-1,4,8,11-tetraazacyclotetradecane). In its free base form, this compound displays rapid intramolecular photoinduced electron transfer (PET) quenching of the anthracene emission, with both the secondary amines and the DMAB group capable of acting as electron donors. When complexed with $\mathrm{Zn}$ (II), the characteristic fluorescence of the anthracene chromophore is restored as the former of these pathways is deactivated by coordination. Importantly, it is shown that the DMAB group, which remains uncoordinated and PET active, acts only very weakly to quench emission, by comparison to the behavior of a model $\mathrm{Zn}$ complex lacking the pendant DMAB group, $\left[\mathrm{ZnL}^{2}\right]^{2+}$ (Chart 1). By contrast, Stern-Volmer analysis of intermolecular quenching of $\left[\mathrm{ZnL}^{2}\right]^{2+}$ by $N, N-$ dimethylaniline (DMA) has shown that this reaction is diffusion limited. Hence, the pivotal role of the bridge in influencing intramolecular PET is highlighted.
\end{abstract}

\section{Introduction}

Photoinduced Electron Transfer (PET) reactions are one of the most important nonradiative decay processes for electronically excited molecules. ${ }^{1}$

$$
\mathrm{D}+\mathrm{A} \stackrel{h v}{\longrightarrow} \mathrm{D}^{*}+\mathrm{A} \stackrel{k_{\mathrm{PET}}}{\longrightarrow} \mathrm{D}^{+}+\mathrm{A}^{-}
$$

The photoexcited species may act as either the electron donor or acceptor resulting in either oxidative or reductive quenching of an excited state. An emergent theme in supramolecular photochemistry has been the enhancement of reactivity for a given reaction by the incorporation of a covalent or noncovalent linkage between interacting subunits as illustrated by eq 2 .

$$
\mathrm{D}-\mathrm{L}-\mathrm{A} \stackrel{h v}{\longrightarrow} \mathrm{D}^{*}-\mathrm{L}-\mathrm{A} \stackrel{k_{\mathrm{PET}}}{\longrightarrow} \mathrm{D}^{+}-\mathrm{L}-\mathrm{A}^{-}
$$

There are several literature examples which use a combination of the anthracene chromphore as a photoactive electron acceptor and an $N, N$-dimethylaniline (DMA) moiety as electron donor for studies of intramolecular PET. For example, the simple alkyl linked systems (1), as shown in Chart 1, have been investigated for their propensity toward intramolecular exciplex formation ${ }^{2}$ and the subsequent charge-transfer interactions of their excited states. ${ }^{3}$ More recently, Mataga et al. ${ }^{4}$ have investigated these systems using time-resolved spectroscopic techniques in the picosecond and femtosecond time domains. The magnitude of

* Corresponding author e-mail: EGMoore@lbl.gov. Current address: Lawrence Berkeley National Laboratory, 1 Cyclotron Rd, Mail Stop 70A1150, Berkeley, CA 94720.

University of Queensland.

$\doteqdot$ University of Geneva. the electronic coupling between donor and acceptor was found to be strongly influenced by increasing the length of the alkyl chain linker, leading to an attenuation of the observed PET rate constants from $\sim 10^{12}$ to $10^{11} \mathrm{~s}^{-1}$ as $n$ increased from 1 to 3 . For the rigidly linked system (2) (Chart 1), emission from the chromophore is bathochromically shifted with increasing solvent polarity, behavior typically ascribed to an exciplex. ${ }^{5}$ However, the bicyclic bridge in this case hinders the large changes in molecular geometry normally requisite for exciplex formation. The dipole moment calculated for (2) in the first excited singlet state is greater than $20 \mathrm{D}$, suggesting complete charge separation occurs upon excitation and the observed emission results from radiative charge recombination. From the rise time of the emission $(\sim 15 \mathrm{ps})$ a corresponding PET rate constant, $k_{\mathrm{PET}}$, of $\sim 10^{11} \mathrm{~s}^{-1}$ may be calculated.

Alternatives to these simple linkages such as the flexible alkylamino 'tren' ligand (3) appended with the 4-dimethylaminobenzyl (DMAB) and 9-anthracenylmethyl donor-acceptor pair have also been recently reported by Bruseghini et al., together with an analogous compound lacking the appended DMAB components. ${ }^{6}$ Under alkaline conditions, emission from the anthracene chromophore is reductively quenched via a PET mechanism involving free alkylamines as electron donors. This reaction is deactivated by protonation under acidic conditions or upon complexation with $\mathrm{Zn}(\mathrm{II})$. However, the fluorescence profile for the $\mathrm{Zn}$ (II) complex of (3) differed significantly to that of the control system lacking the DMAB moieties, due to the presence of an alternate PET quenching pathway, with DMAB acting as the electron donor. This pathway was largely deactivated by the addition of triphenylacetate, which axially coordinates to $\mathrm{Zn}(\mathrm{II})$ via the carboxylate group. Hence, the authors were able to ascribe a 'through-space' mechanism to 
CHART 1. Compounds Relevant to This Study

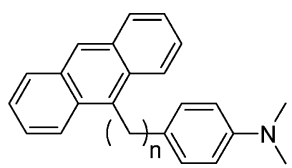

(1)

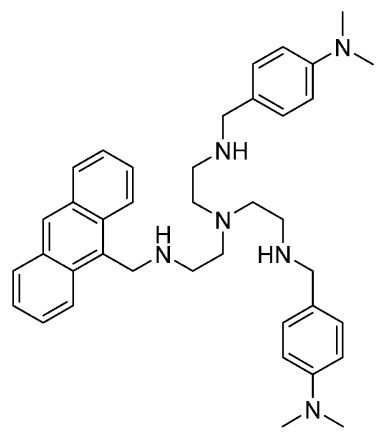

(3)

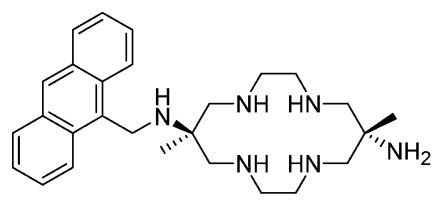

$\left(\mathrm{L}^{2}\right)$

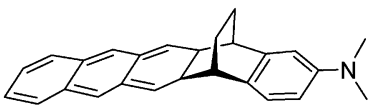

(2)

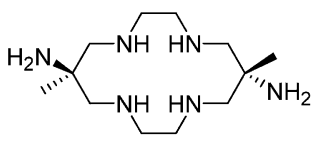

$\left(L^{1}\right)$

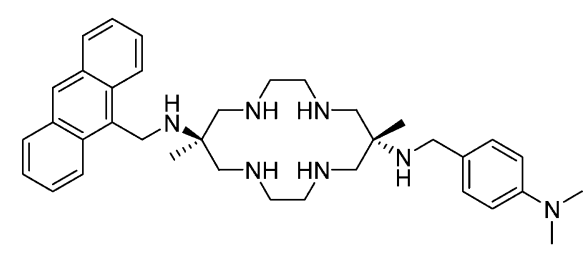

$\left(L^{3}\right)$ the observed PET quenching reaction, which was blocked by intercalation of the anion. ${ }^{6}$

Herein, we describe the photophysical behavior of $\mathrm{L}^{3}$ (Chart 1), a rare example of a macrocyclic system with an appended photoactive chromophore and suitable electron donor, facilitating its use as a probe for the study of intramolecular PET. This compound is also the first example of a system whereby these two asymmetric components have been introduced via initial C-substitution of the cyclam core with pendant primary amino groups, which may be subsequently funtionalized with ease. As a result, the anticipated coordination tendencies of the macrocycle will remain essentially unaffected by this synthetic modification, allowing facile complexation with a variety of first row transition-metal cations (such as $\mathrm{Zn}$ (II), vide infra) using well known cyclam chemistry.

\section{Experimental Section}

Synthesis. Synthetic procedures employed for the preparation of the parent $\mathrm{L}^{1}$ macrocycle in its free base form and the monosubstituted 9-anthracenylmethyl derivative, $\mathrm{L}^{2}$, have been previously described. ${ }^{7,8}$ Corresponding $\mathrm{Zn}$ (II) complexes were generated in situ by titration with $\sim 1.1$ equiv of $\mathrm{Zn}\left(\mathrm{ClO}_{4}\right)_{2}$. $6 \mathrm{H}_{2} \mathrm{O}$. Unless otherwise stated, all other reagents were obtained commercially and used without further purification.

6-((Anthracen-9-yl-methyl)amino)-trans-6,13-dimethyl-13((4-dimethylaminobenzyl)amino)-1,4,8,11-tetraazacyclotetradecane, $\mathbf{L}^{3}$. $\mathrm{L}^{1}(0.52 \mathrm{~g}, 2.0 \mathrm{mmol})$ was melted at $150{ }^{\circ} \mathrm{C}$ in a $50 \mathrm{~mL}$ round-bottomed flask and stirred. Solid 4-dimethylaminobenzaldehyde $(0.30 \mathrm{~g}, 2.0 \mathrm{mmol})$ was added, and a stream of air was passed across the top of the reaction vessel to remove liberated water vapor. The reactants were stirred for ca. $30 \mathrm{~min}$, during which time they solidified to give a toffeelike solid. In a separate flask, $\mathrm{NaBH}_{4}(0.23 \mathrm{~g}, 6.0 \mathrm{mmol})$ was dissolved in dry EtOH $(25 \mathrm{~mL})$, which was then added in portions to the crude product as it cooled. This solution was stirred for $2 \mathrm{~h}$ at room temperature, then $\mathrm{H}_{2} \mathrm{O}(200 \mathrm{~mL})$ was added, and the resulting suspension was extracted with $\mathrm{CH}_{2} \mathrm{Cl}_{2}(3 \times 75 \mathrm{~mL})$. Removal of the solvent gave an oil, which was redissolved in an $\mathrm{EtOH} / \mathrm{H}_{2} \mathrm{O}$ mixture $(9: 1$, v/v, $200 \mathrm{~mL})$, and $\mathrm{HCl}(1 \mathrm{M})$ was added until the $\mathrm{pH}$ of the resulting solution was 6.3 . $\mathrm{Na}[\mathrm{CN}$ $\left.\left(\mathrm{BH}_{3}\right)\right](0.38 \mathrm{~g}, 6.0 \mathrm{mmol})$ was added, resulting in precipitation of a white powder which was removed via filtration and subsequently identified by ${ }^{1} \mathrm{H}$ NMR to be the cyanoborohydride salt of the symmetrically disubstituted bis(4-dimethylamino)benzyl $\mathrm{L}^{1}$ adduct. To the filtrate was added anthracene-9carbaldehyde $(0.31 \mathrm{~g}, 2.0 \mathrm{mmol})$ which was dissolved separately in $\mathrm{EtOH}(50 \mathrm{~mL})$, and the resulting solution was stirred at room temperature for $2 \mathrm{~h}$ while maintaining the $\mathrm{pH}$ at ca. 6.3 by the addition of aliquots of $\mathrm{HCl}(1 \mathrm{M})$ as required. This solution was then left to stir overnight to give a precipitate of the desired product as the cyanoborohydride salt $\left[\mathrm{H}_{2} \mathrm{~L}^{3}\right]\left[(\mathrm{CN}) \mathrm{BH}_{3}\right]_{2}$. This was collected by vacuum filtration then converted to its free base form by suspending in $\mathrm{NaOH}(1 \mathrm{M}, 200 \mathrm{~mL})$ followed by extraction with $\mathrm{CH}_{2} \mathrm{Cl}_{2}$. The organic layer was dried over $\mathrm{Na}_{2}-$ $\mathrm{SO}_{4}$, and removal of the solvent gave an oil which was recrystallized from a $1: 1$ mixture of $\mathrm{CH}_{2} \mathrm{Cl}_{2}: \mathrm{CH}_{3} \mathrm{CN}$ (v/v) to give a pale yellow solid which was filtered and washed with $\mathrm{Et}_{2} \mathrm{O}(0.37 \mathrm{~g}, 0.63 \mathrm{mmol}, 31.4 \%)$. Elemental analysis: Found C, 71.97; H, 8.89; N, 16.39\% Calcd C, 72.08; H, 8.91; N, $16.34 \%$ for $\mathrm{C}_{36} \mathrm{H}_{51} \mathrm{~N}_{7} \cdot 1 \mathrm{H}_{2} \mathrm{O}$ NMR: ${ }^{1} \mathrm{H}:\left(\mathrm{CDCl}_{3}\right) \delta 1.11(\mathrm{~s}, 3 \mathrm{H}$, $\left.\mathrm{CH}_{3}\right), 1.40$ (s, 3H, $\left.\mathrm{CH}_{3}\right), 2.1$ (s br, 6H, NH), 2.4-2.9 (m, 16H, $\mathrm{CH}_{2}$-macrocyclic), 3.62 (s, 2H, N- $\mathrm{CH}_{2}$-DMA), 4.64 (s, 2H, $\mathrm{N}-\mathrm{CH}_{2}$-Anth), 6.70 (d, 2H), 7.22 (d, 2H), 7.4-7.5 (m, 4H), $7.97(\mathrm{~d}, 2 \mathrm{H}), 8.42(\mathrm{~s}, 1 \mathrm{H}), 8.43(\mathrm{~d}, 2 \mathrm{H}) \mathrm{ppm} .{ }^{13} \mathrm{C}:\left(\mathrm{CDCl}_{3}\right) \delta$ 
$23.01,23.05,38.1,40.9,45.6,48.7,48.9,55.1,55.9,57.55$, $57.63,112.9,124.5,124.9,125.8,127.0,129.0,129.1,129.5$, $130.4,131.7,132.2,149.82 \mathrm{ppm}$. X-ray quality crystals were obtained by slow evaporation of this product from a $1: 1(\mathrm{v} / \mathrm{v})$ $\mathrm{CH}_{2} \mathrm{Cl}_{2}: \mathrm{CH}_{3} \mathrm{CN}$ solvent mixture.

Physical Methods. Nuclear magnetic resonance spectra were measured at $400.13\left({ }^{1} \mathrm{H}\right)$ and $100.62 \mathrm{MHz}\left({ }^{13} \mathrm{C}\right)$ on a Bruker AV400 spectrometer using a 1:1 $\mathrm{CD}_{3} \mathrm{CN} / \mathrm{CD}_{3} \mathrm{Cl}(\mathrm{v} / \mathrm{v})$ solvent mixture and referenced to the residual $\mathrm{CHD}_{2} \mathrm{CN}$ solvent peak at $1.96 \mathrm{ppm}$ vs TMS. Electronic absorption spectra were measured on a Perkin-Elmer Lambda 40 spectrophotometer using quartz cells. Steady-state emission and excitation spectra were collected on a Perkin-Elmer LS-50B spectrofluorimeter. Samples were purged with $\mathrm{N}_{2}$ prior to measurements, and cut off filters were employed to avoid detection of higher order excitation light. Electrochemical measurements were performed using a BAS100B/W potentiostat with a Pt wire auxiliary electrode, $\mathrm{a} \mathrm{Ag} / \mathrm{AgNO}_{3}(0.01 \mathrm{M}$ in $\mathrm{DMF})$ nonaqueous reference electrode, and a glassy carbon working electrode. All solutions utilized DMF as the solvent for enhanced solubility, were purged with $\mathrm{N}_{2}$ prior to measurements, and contained ca. $5 \times 10^{-3} \mathrm{M}$ analyte with $0.1 \mathrm{M} \mathrm{Et}_{4} \mathrm{NClO}_{4}$ as the supporting electrolyte. Measured potentials were referenced to the ferrocene-ferrocenium couple, which was used as an external standard.

Fluorescence lifetimes were determined by time-correlated single photon counting (TCSPC) measurements using an experimental setup similar to that previously described. ${ }^{9}$ An excitation wavelength of $395 \mathrm{~nm}$ was achieved with a pulsed laser diode (Picoquant, LDH-P-C-400B). The average power at $20 \mathrm{MHz}$ was $0.5 \mathrm{~mW}$, and the pulse duration was about 65 ps. Solution concentrations were $\sim 10^{-5} \mathrm{M}$ in analyte, which, if necessary, were further diluted to maintain an optical density of no more than 0.1 at the excitation wavelength, and samples were degassed thoroughly by purging with $\mathrm{N}_{2}$ prior to each measurement. The measured full width at half-maximum (fwhm) for the instrument response function (IRF) of this experimental setup was less than 200 ps. Observed fluorescence time profiles were analyzed by iterative reconvolution with the measured instrument response functions using a nonlinear least-squares fitting procedure.

The fluorescence upconversion setup was based on the commercially available FOG100 system (CDP, Laser \& Scanning Systems) and has been described in detail previously. ${ }^{10}$ An excitation wavelength of $395 \mathrm{~nm}$ was achieved using the frequency doubled output of Kerr lens mode-locked Ti:Sapphire laser (Tsunami, Spectra-Physics). The full width at halfmaximum (fwhm) of the instrument response function (IRF) for this setup was ca. $210 \mathrm{fs}$. Fluorescence time profiles were analyzed using a nonlinear least-squares fitting procedure.

The experimental setup used to perform picosecond multiplex transient grating experiments has also been described in detail elsewhere. ${ }^{11,12}$ In this case, the excitation (pump pulse) was achieved with the third harmonic output at $355 \mathrm{~nm}$ of an active/ passive mode-locked Q-switched Nd:YAG laser with a single amplification stage (Continuum, PY61-10). The duration of the pulses was about $25 \mathrm{ps}$, and the pump intensity on the sample was on the order of $2 \mathrm{~mJ} / \mathrm{cm}^{2}$. The time resolution of this experimental setup was ca. $30 \mathrm{ps}$.

Molecular modeling of $\left[\mathrm{ZnL}^{3}\right]^{2+}$ was performed with MOMEC $97^{13}$ using previously reported force field parameters ${ }^{14}$ to evaluate likely solution conformations. Drawings of modeled structures were produced with RASMOL. ${ }^{15,16}$

Crystallography. Cell constants were determined by a leastsquares fit to the setting parameters of 25 independent reflections

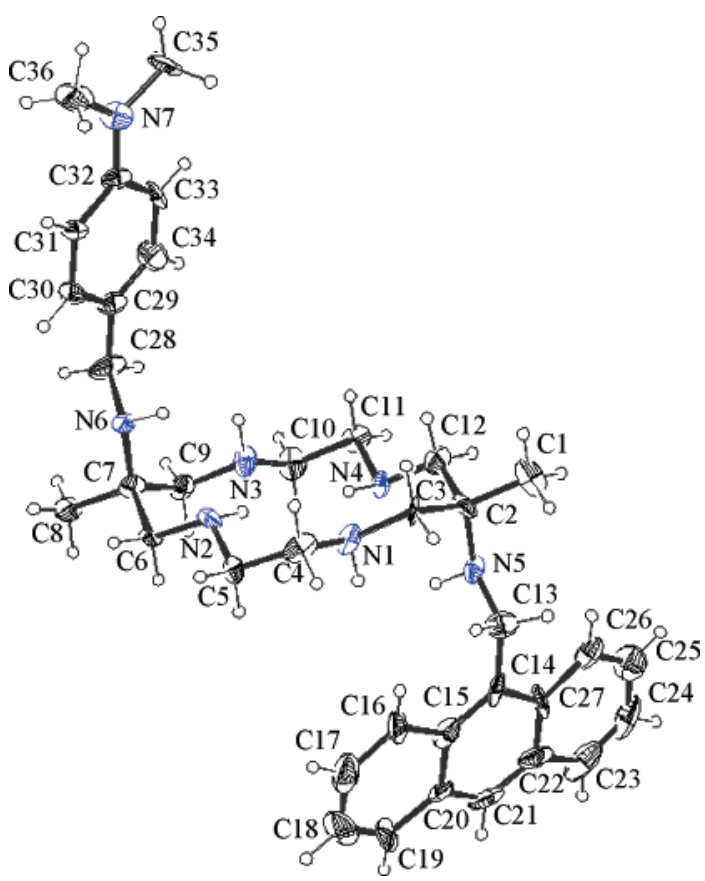

Figure 1. X-ray crystal structure of $\mathrm{L}^{3}$ (30\% probability ellipsoids shown).

measured on an Enraf-Nonius CAD4 four circle diffractometer employing graphite monochromated $\mathrm{Mo}-\mathrm{K} \alpha$ radiation $(0.71073$ $\AA$ ) and operating in the $\omega-2 \theta$ scan mode. Data reduction and empirical absorption corrections ( $\psi$-scans) were performed with the WINGX ${ }^{17}$ package. The structure was solved by direct methods with SHELXS- $86^{18}$ and refined by full-matrix leastsquares analysis with SHELXL-97. ${ }^{19}$ The drawing of the molecule was produced with ORTEP-3. ${ }^{20}$

Crystal Data. 6-((9-Anthracenylmethyl)amino)-trans-6,13dimethyl-13-((4-dimethylaminobenzyl)amino)-1,4,8,11-tetraazacyclotetradecane, $\mathrm{C}_{36} \mathrm{H}_{51} \mathrm{~N}_{7}, 581.84 \mathrm{~g} \cdot \mathrm{mol}^{-1}$, monoclinic, $a=$ 9.2709(9), $b=32.431(3), c=11.698(2) \AA, \beta=110.714(7)^{\circ}$, $V=3289.8(7) \AA^{3}, T=293 \mathrm{~K}$, space group $P 2_{1} / a$ (No. 14, variant of $\left.P 2_{1} / c\right), Z=4, \mu($ Mo $\mathrm{K} \alpha)=0.71 \mathrm{~cm}^{-1}, 6136$ reflections measured, 5758 unique $\left(R_{\text {int }}=0.1630\right)$ which were used in all calculations, $R_{1}=0.0627$ (for obs. data, $I>2 \sigma(\mathrm{I})$, $\mathrm{w} R_{2}=0.2400$ (all data).

\section{Results}

X-ray Crystallography. Crystals of $\mathrm{L}^{3}$ suitable for structural characterization were obtained, and a view of the molecule is shown in Figure 1. The appended 4-dimethylaminobenzyl (DMAB) and 9-anthracenylmethyl groups are essentially planar, with a maximum deviation apparent for $\mathrm{C} 31$ of $0.015 \AA$ in the former case, and a maximum deviation of $0.052 \AA$ for $\mathrm{C} 25$ in the latter. The nitrogen atom of the DMAB moiety is $\mathrm{sp}^{2}$ hybridized, indicated by the terminal $\mathrm{H}_{3} \mathrm{C}-\mathrm{N}-$ phenyl and $\mathrm{H}_{3} \mathrm{C}-\mathrm{N}-\mathrm{CH}_{3}$ angles, which are ca. $121.9^{\circ}, 120.0^{\circ}$, and $118.0^{\circ}$. As such, the lone pair of N7 is delocalized throughout the $\pi$ system, and the terminal phenyl-N7 bond length (1.36 $\AA$ ) is indicative of a bond order greater than one. The alkyl $\mathrm{C}-\mathrm{C}$ and $\mathrm{C}-\mathrm{N}$ bond lengths of the macrocyclic linker are typical, and the substituted propane diamine sections form a pseudochair configuration if $\mathrm{H}$-bonds involving the adjacent secondary amines are included (e.g. N2- H2 $\cdots \mathrm{N} 3 \quad 2.24 \AA$ and $\mathrm{N} 4-\mathrm{H} 4 \cdots \mathrm{N} 12.21 \AA$ A). Ancillary H-bonding interactions between adjacent macrocyclic secondary amino groups (e.g. $\mathrm{N} 2-\mathrm{H} 2 \cdots \mathrm{N} 1 \quad 2.45 \AA$ and $\mathrm{N} 4-\mathrm{H} 4 \cdots \mathrm{N} 3 \quad 2.46 \AA$ ) and the exocyclic amine protons with endocyclic amine lone pairs are 


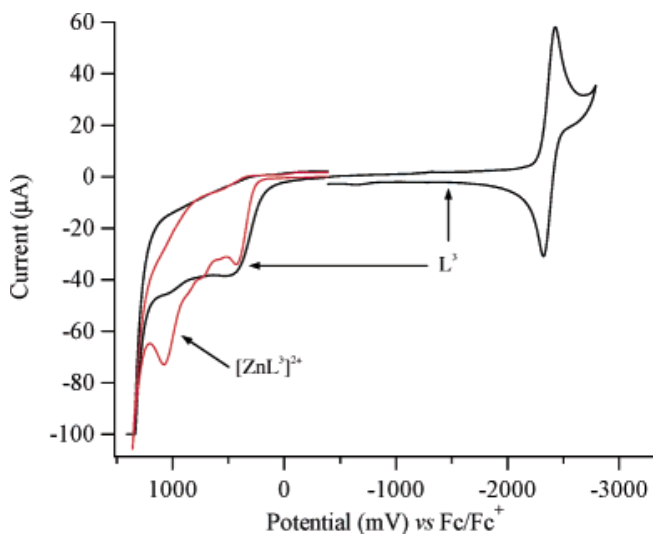

Figure 2. Cyclic voltammograms of $\mathrm{L}^{3}$ and $\left[\mathrm{ZnL}^{3}\right]^{2+}$ (anodic sweep only, see text) in DMF at $298 \mathrm{~K}$

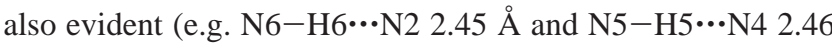
$\AA$ ). No other close contacts indicating intra- or intermolecular interactions were observed.

Electrochemistry. Electrochemical measurements were performed by cyclic voltammetry for $\mathrm{L}^{3}$ and its $\mathrm{Zn}$ (II) complex utilizing DMF as the solvent with the resulting voltammograms as shown in Figure 2. For $\mathrm{L}^{3}$, a single electron reversible wave was observed in the reductive sweep at a potential of -2380 $\mathrm{mV} \mathrm{vs} \mathrm{Fc}^{+/ 0}$, which was assigned to electrochemical generation of the anthracene radical monoanion and compares well to previously reported values. ${ }^{21}$ In the oxidative sweep, very broad irreversible waves, assigned to amine oxidation processes, were observed with a potential range from $+300 \mathrm{mV}$ to $+1000 \mathrm{mV}$. As a consequence, the wave corresponding to electrochemical oxidation of the appended 4-dimethylaminobenzyl moiety was obscured compared to the analogous process for $N, N$-dimethylaniline, which appeared at $+450 \mathrm{mV}$ under identical conditions.

Upon complexation with $\mathrm{Zn}(\mathrm{II})$, the amine oxidation potentials are anodically shifted, as evident from an irreversible wave at ca. $+1000 \mathrm{mV}$. As a result, for $\left[\mathrm{ZnL}^{3}\right]^{2+}$, electrochemical generation of the radical cation for the appended 4-dimethylaminobenzyl moiety is more readily apparent as an irreversible wave at ca. $+430 \mathrm{mV}$. The electrochemical response for the $\mathrm{Zn}$ (II) complex in the reductive sweep was complicated by the onset of electrodeposition of elemental zinc on the electrode surface, at ca. $-1400 \mathrm{mV}$, coupled with a correspondingly broad anodic stripping wave at ca. $-1000 \mathrm{mV}$ (data not shown). As a consequence, the redox potentials for electrochemical generation of the anthracene radical anion for the $\mathrm{Zn}$ (II) complex could not be obtained.

Steady-State Photophysical Measurements. Electronic absorption spectra of the free ligand, $\mathrm{L}^{3}$, and the corresponding $\mathrm{Zn}$ (II) complex were measured in $\mathrm{CH}_{3} \mathrm{CN}$ solution and are essentially indistinguishable. The spectrum of the latter is shown in Figure 3, together with the electronic spectra of the monosubstituted $\left[\mathrm{ZnL}^{2}\right]^{2+}$ analogue. For both complexes, the spectra are dominated by intense absorptions in the UV region. By reference to the parent chromophore, ${ }^{22}$ the sharp peak at 254 $\mathrm{nm}$ may be assigned to the $\mathrm{S}_{0} \rightarrow \mathrm{S}_{3}$ transition of the anthracene chromophore, while the $\mathrm{S}_{0} \rightarrow \mathrm{S}_{1}$ transition for this chromophore is evident at lower energy as a vibronic progression with an origin at ca. $385 \mathrm{~nm}$ and additional peaks separated by ca. 1420 $\mathrm{cm}^{-1}$. The $\mathrm{S}_{0} \rightarrow \mathrm{S}_{2}$ band of the anthracene chromophore is only weakly electric dipole allowed and was not observed. For the 4-dimethylaminobenzyl chromophore, the $S_{0} \rightarrow S_{2}$ transition is masked by the anthracene $S_{0} \rightarrow S_{3}$ transition yet is manifest by a significant broadening of the latter peak on the low energy side at ca. $270 \mathrm{~nm}$ when compared to the corresponding

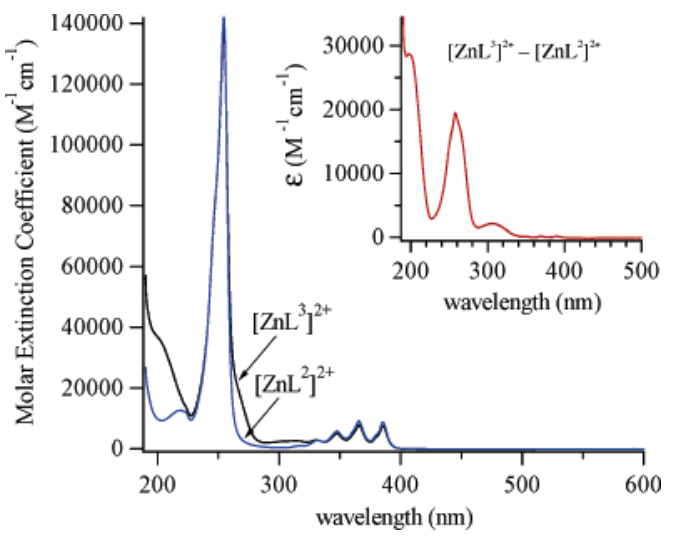

Figure 3. $\mathrm{UV}-$ visible absorption spectra of $\left[\mathrm{ZnL}^{3}\right]^{2+}$ and $\left[\mathrm{ZnL}^{2}\right]^{2+}$ compound in $\mathrm{CH}_{3} \mathrm{CN}$ at $298 \mathrm{~K}$. Inset: Corrected difference spectrum showing DMA centered absorption bands (see text).

spectrum for the monosubstituted $\left[\mathrm{ZnL}^{2}\right]^{2+}$ analogue (Figure 3). A second broad band is evident at ca. $310 \mathrm{~nm}$, overlapping the anthracene $S_{0} \rightarrow S_{1}$ transition, which may be assigned to the 4-dimethylaminobenzyl $S_{0} \rightarrow S_{1}$ band. The bands for this chromophore are particularly evident in the difference spectrum between $\left[\mathrm{ZnL}^{3}\right]^{2+}$ and $\left[\mathrm{ZnL}^{2}\right]^{2+}$ which is shown as an inset of Figure 3. This corrected difference spectrum also reveals a third band at ca. $198 \mathrm{~nm}$ and is in agreement with the reported spectra for para-substituted $N, N$-dimethylaniline derivatives. ${ }^{23,24}$

The emission spectrum of the free ligand, $\mathrm{L}^{3}$, in its free base form, was characteristically weak due to significant PET quenching, with both the appended 4-dimethylaminobenzyl group and the macrocyclic amine lone pairs capable of acting as electron donors. By contrast, the emission spectrum of $\left[\mathrm{ZnL}^{3}\right]^{2+}\left(\lambda_{\mathrm{ex}}=365 \mathrm{~nm}\right)$, as shown in Figure 4 , is characteristic of the appended anthracene chromophore, with an origin at ca. $390 \mathrm{~nm}$, a maximum intensity at ca. $413 \mathrm{~nm}$, and several other peaks of a Franck Condon vibrational progression clearly observed. The corresponding excitation spectrum $\left(\lambda_{\mathrm{em}}=413\right.$ $\mathrm{nm}$ ) was found to be essentially identical to that of the monosubstituted $\left[\mathrm{ZnL}^{2}\right]^{2+}$ complex. Notably, the fluorescence quantum yield of $\left[\mathrm{ZnL}^{3}\right]^{2+}$, as determined by the optically dilute method $^{25}$ by comparison to the parent chromophore, was $\Phi_{\mathrm{f}}=$ 0.14 which is slightly diminished compared to that reported previously for $\left[\mathrm{ZnL}^{2}\right]^{2+}$ of $\Phi_{\mathrm{f}}=0.19$.

Hence, additional steady-state emission measurements were performed with the $\left[\mathrm{ZnL}^{2}\right]^{2+}$ complex in the presence of $N, N$ dimethylaniline (DMA) to assess the propensity for quenching of anthracene fluorescence by the intermolecular reaction.

$$
\left[\mathrm{Zn}\left(\mathrm{L}^{2}\right)\right]^{2+}+\mathrm{DMA} \stackrel{\mathrm{PET}}{\longrightarrow}\left[\mathrm{Zn}\left(\mathrm{L}^{2}\right)^{(\bullet-)}\right]^{2+}+\mathrm{DMA}^{(\bullet+)}
$$

The resulting emission spectra in the presence of increasing DMA concentrations are shown in Figure 5 where a decrease in the anthracene fluorescence intensity with increasing quencher concentration is clearly demonstrated. Also shown as an inset is the corresponding Stern-Volmer plot of $I_{\mathrm{F}}{ }^{0} / I_{\mathrm{F}}$ vs $[\mathrm{DMA}]$, where $I_{\mathrm{F}}$ and $I_{\mathrm{F}}{ }^{0}$ represent the fluorescence intensity in the presence and absence of quencher, respectively. This data set displayed a pronounced upward curvature at high concentrations of quencher, indicative of both dynamic and static quenching effects. Behavior of this type may be due to a ground-state association of $\left[\mathrm{ZnL}^{2}\right]^{2+}$ with the DMA quencher or, alternately, due to the so-called transient effect, ${ }^{26}$ whereby a proportion of the quencher is in sufficient proximity for PET quenching to occur at the instant of excitation. ${ }^{27,28}$ In the present case, since there was no observable change to the electronic spectrum of 


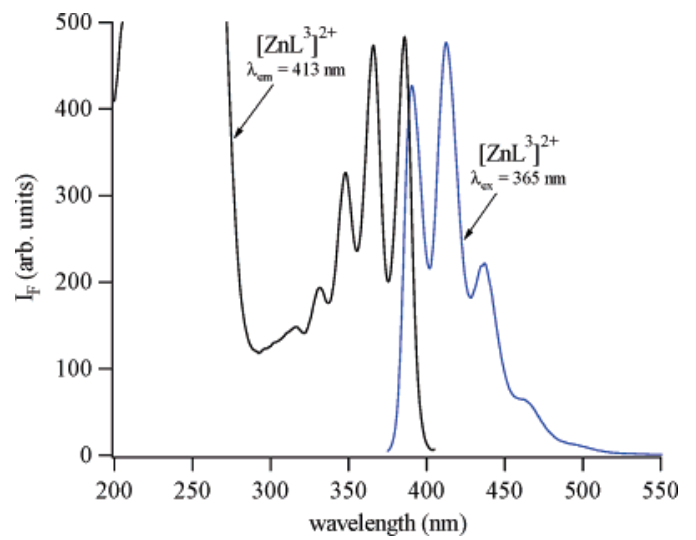

Figure 4. Emission and excitation spectra of $\left[\mathrm{ZnL}^{3}\right]^{2+}$ in $\mathrm{CH}_{3} \mathrm{CN}$ at $298 \mathrm{~K}$.

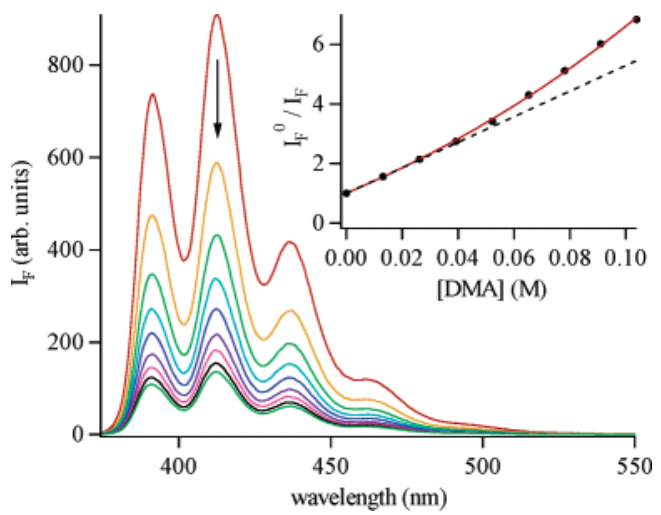

Figure 5. Decreases in $\left[\mathrm{ZnL}^{2}\right]^{2+}$ fluorescence due to bimolecular PET quenching (see eq 3 ) with increasing dimethylaniline (DMA) concentration in $\mathrm{CH}_{3} \mathrm{CN}$ at $298 \mathrm{~K}$. Inset: Stern-Volmer plot of $I_{\mathrm{F}}{ }^{0} / I_{\mathrm{F}}$ at $413 \mathrm{~nm}$ with increasing [DMA] and least-squares fit (solid line) to eq 4.

TABLE 1: Summary of Fluorescence Decay Parameters for $\mathrm{L}^{2}, \mathrm{~L}^{3}$, and Their $\mathrm{Zn}(\mathrm{II})$ Complexes Measured by TCSPC in 1:1 (v/v) $\mathrm{CH}_{3} \mathrm{CN}$ :Toluene at $298 \mathrm{~K}$

\begin{tabular}{lccll}
\hline \multicolumn{1}{c}{ compd } & $\tau_{1}(\mathrm{~ns})$ & $\tau_{2}(\mathrm{ps})$ & $\tau_{3}(\mathrm{ps})$ & $A_{1} / A_{2}$ \\
\hline $\mathrm{L}^{2}$ & $2.0 \pm 0.10$ & $170 \pm 8.5$ & $\ll \mathrm{IRF}$ & 0.3 \\
$\mathrm{~L}^{3}$ & $1.4 \pm 0.07$ & $140 \pm 7.0$ & $\ll \mathrm{IRF}$ & 0.05 \\
{$\left[\mathrm{ZnL}^{2}\right]^{2+}$} & $5.0 \pm 0.25$ & N/A & N/A & N/A \\
{$\left[\mathrm{ZnL}^{3}\right]^{2+}$} & $4.1 \pm 0.21$ & N/A & N/A & N/A
\end{tabular}

the anthracene chromophore in the presence of DMA to suggest a ground-state association, the data were fit to the latter model using an appropriately modified nonlinear form of the SternVolmer equation ${ }^{26}$

$$
\frac{I_{\mathrm{F}}{ }^{0}}{I_{\mathrm{F}}}=1+K_{\mathrm{sv}}[\mathrm{Q}] \exp \left(\gamma V N_{\mathrm{A}}[\mathrm{Q}]\right)
$$

where $I_{\mathrm{F}}{ }^{0}$ and $I_{\mathrm{F}}$ represent the fluorescence intensity in the absence and presence of a given quencher concentration, [Q], respectively, $N_{\mathrm{A}}$ is Avogadro's number, and $V$ is the volume $\left(\mathrm{m}^{3}\right)$ around the fluorophore wherein quenching occurs with unit efficiency $(\gamma=1)$. The resulting best fit values for $K_{\mathrm{sv}}$ and $\gamma V$ were $39.9 \pm 0.99 \mathrm{M}^{-1}$ and $5.66 \pm 0.47 \times 10^{-24} \mathrm{~m}^{3}$ respectively.

Time-Resolved Photophysical Measurements. Time-resolved fluorescence decay profiles for $\mathrm{L}^{3}$ and the corresponding $\mathrm{Zn}$ (II) complex generated in situ were measured by the TCSPC technique in a $1: 1(\mathrm{v} / \mathrm{v})$ mixture of $\mathrm{CH}_{3} \mathrm{CN}$ and toluene, with resulting decay parameters as summarized in Table 1. Corresponding parameters for $\mathrm{L}^{2}$ measured under identical conditions are also shown. The decay profiles of both ligands were
TABLE 2: Summary of Ultrafast Fluorescence Decay Parameters for $\mathbf{L}^{2}$ and $\mathbf{L}^{3}$ Measured by Fluorescence Upconversion in 1:1 (v/v) $\mathrm{CH}_{3} \mathrm{CN}$ :Toluene at $298 \mathrm{~K}$

\begin{tabular}{ccccccccc}
\hline & & & & \multicolumn{3}{c}{$\tau_{3}$} \\
compd & $\tau_{1}(\mathrm{ps})$ & $A_{1}$ & $\tau_{2}(\mathrm{ps})$ & $A_{2}$ & $(\mathrm{ps})$ & $A_{3}$ & $(\mathrm{~ns})$ & $A_{4}$ \\
\hline $\mathrm{L}^{2}$ & $0.75 \pm 0.038$ & 0.19 & $12 \pm 0.60$ & 0.44 & $170^{a}$ & 0.3 & $2.0^{a}$ & 0.07 \\
$\mathrm{~L}^{3}$ & $0.90 \pm 0.045$ & 0.22 & $9.3 \pm 0.47$ & 0.33 & $140^{a}$ & 0.43 & $1.4^{a}$ & 0.02
\end{tabular}

${ }^{a}$ Fixed to values from TCSPC measurements in the same solvent system.
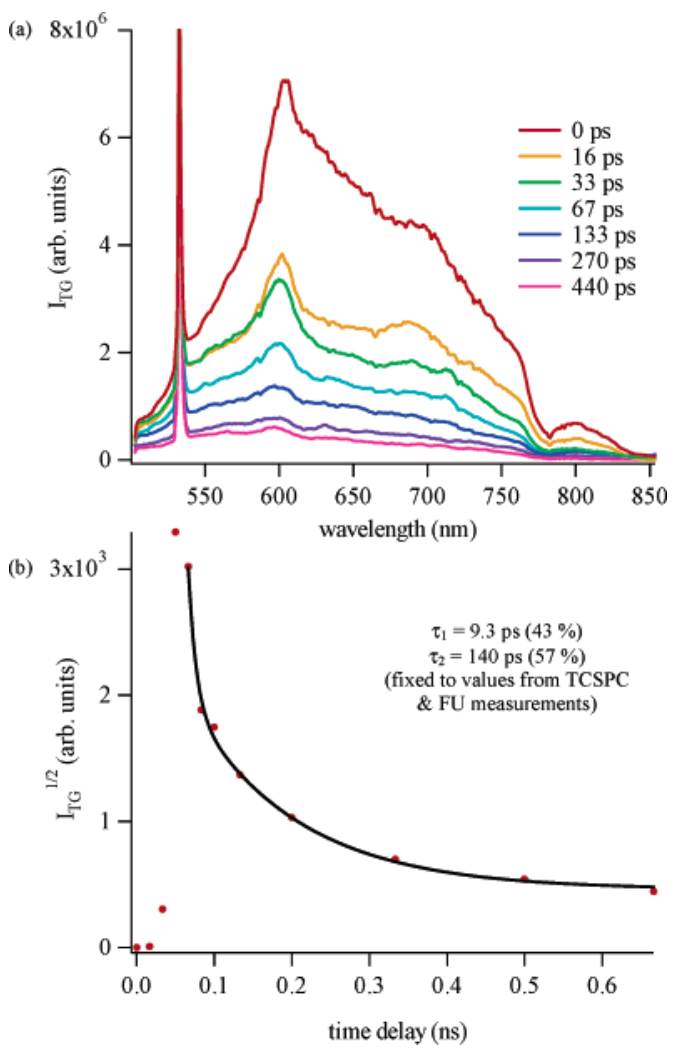

Figure 6. (a) Transient grating spectra of $\mathrm{L}^{3}$ in $1: 1$ (v/v) $\mathrm{CH}_{3} \mathrm{CN}$ : toluene at $355 \mathrm{~nm}$ excitation (the $532 \mathrm{~nm}$ spike is due to the second harmonic of Nd:YAG laser pulses) and (b) time evolution of the square root of the TG intensity at $600 \mathrm{~nm}\left(\mathrm{~S}_{1} \rightarrow \mathrm{S}_{n}\right)$.

nonexponential, requiring a triple exponential function to accurately reflect the data. Indeed, the fastest of these decay processes was less than the time resolution of the TCSPC setup, which necessitated further characterization using the shorter time scale fluorescence upconversion (FU) technique. The resulting FU decay curves (Supporting Information, Figure S1) may, in principle, be reproduced with a biexponential function that plateaus to a nonzero value. However, from TCSPC measurements, we know that this plateau arises due to the presence of the slower decaying components. Hence, the decays were fit to a four exponential function with two lifetimes fixed to the values obtained from TCSPC measurement, and the resulting fit parameters are summarized in Table 2.

In addition to characterizing the temporal profile, the excitedstate population dynamics of $\mathrm{L}^{3}$ and its corresponding $\mathrm{Zn}$ (II) complex were also assessed using the transient grating (TG) technique. As discussed in detail elsewhere, ${ }^{11,12}$ these spectra are very similar to transient absorption spectra, the main difference being that the transient grating intensity is always positive. As shown in Figure 6(a), the TG spectra of $\mathrm{L}^{3}$ consist mainly of a band at $600 \mathrm{~nm}$ with a broad shoulder at ca. 700 $\mathrm{nm}$. The former band at $600 \mathrm{~nm}$ can be assigned to $\mathrm{S}_{1} \rightarrow \mathrm{S}_{n}$ transitions of the anthracene chromophore, in accordance with 

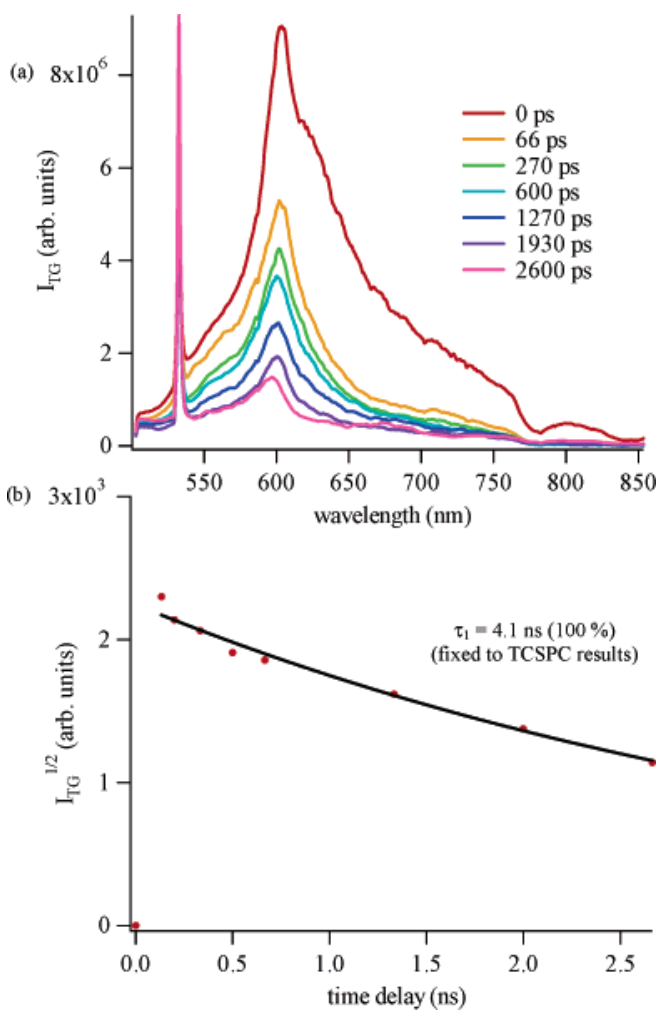

Figure 7. (a) Transient grating spectra of $\left[\mathrm{ZnL}^{3}\right]^{2+}$ in $1: 1(\mathrm{v} / \mathrm{v}) \mathrm{CH}_{3-}$ $\mathrm{CN}$ :toluene at $355 \mathrm{~nm}$ excitation (the $532 \mathrm{~nm}$ spike is due to the second harmonic of Nd:YAG laser pulses) and (b) time evolution of the square root of the TG intensity at $600 \mathrm{~nm}\left(\mathrm{~S}_{1} \rightarrow \mathrm{S}_{n}\right)$.

previously reported spectra. ${ }^{29,30}$ The decay kinetics of this band obtained from the time dependence of the square root of the TG signal (see Figure 6(b)) were consistent with the lifetimes of 9.3 and $140 \mathrm{ps}$, obtained by TCSPC and fluorescence upconversion (FU) measurements in the same solvent system. The shoulder at ca. $700 \mathrm{~nm}$ may be similarly assigned to the anthracene radical anion. ${ }^{31}$ This band is quite weak and displays decay kinetics that are more rapid than the $600 \mathrm{~nm}$ band, indicating the subsequent charge recombination (back electron transfer) process is faster than the initial photoinduced electron transfer, resulting in only a small population of charge separated compounds. Upon complexation to $\mathrm{Zn}(\mathrm{II})$, the $\mathrm{PET}$ reaction involving macrocyclic amine donors is deactivated, and the corresponding TG spectra (Figure 7(a)) display only a single band at $600 \mathrm{~nm}$ ascribed to $\mathrm{S}_{1} \rightarrow \mathrm{S}_{n}$ of the anthracene chromophore, the decay kinetics of which were satisfactorily reproduced by a single-exponential decay with a $4.1 \mathrm{~ns}$ lifetime as determined by TCSPC measurements. More importantly, the TG spectra for $\left[\mathrm{ZnL}^{3}\right]^{2+}$ showed no evidence of an anthracene radical anion absorption band.

Time-resolved TG measurements were also performed for the intermolecular PET reaction between $\left[\mathrm{ZnL}^{2}\right]^{2+}$ and $N, N$ dimethylaniline (eq 3), the results of which are shown in Figure 8. In this case, both the reactant, $\left[\mathrm{Zn}\left(\mathrm{L}^{2}\right)^{*}\right]^{2+}$, and product, $\left[\mathrm{Zn}\left(\mathrm{L}^{2}\right)^{(-)}\right]^{1+}$, of the intermolecular PET reaction are evident. The former is apparent as the band at $600 \mathrm{~nm}$, assigned to anthracene $S_{1} \rightarrow S_{n}$ excited-state transitions. ${ }^{29,30}$ This band rapidly decays with kinetics that were fit to a single exponential $\left(\tau_{1} \sim 450 \mathrm{ps}\right)$ to form a new broad band with maxima at ca. 660 and $750 \mathrm{~nm}$. The rise time of this absorption agrees well with the decay of the anthracene $S_{1}$ excited-state population, and its appearance may be attributed to anthracene radical anion formation. ${ }^{31}$ Considering the polarity of the solvent and the fact that this band does not exhibit a significant decay in the time
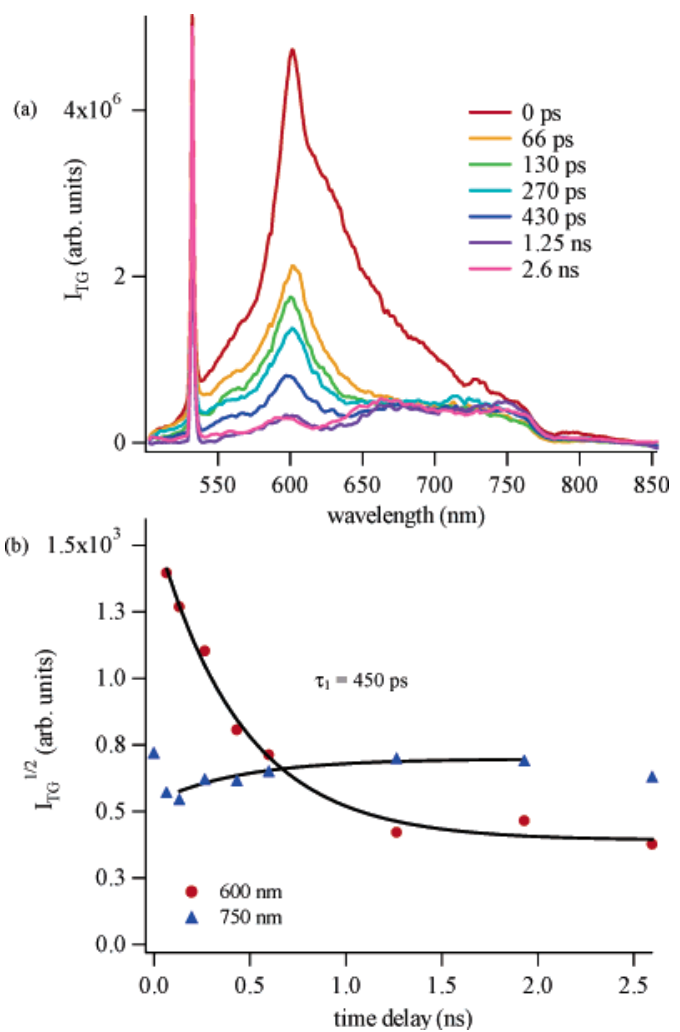

Figure 8. (a) Transient grating spectra of $\left[\mathrm{ZnL}^{2}\right]^{2+}+0.1 \mathrm{M}$ DMA in $1: 1(\mathrm{v} / \mathrm{v}) \mathrm{CH}_{3} \mathrm{CN}$ :toluene at $355 \mathrm{~nm}$ excitation (the $532 \mathrm{~nm}$ spike is due to the second harmonic of Nd:YAG laser pulses) and (b) time evolution of the square root of the TG intensity at $600 \mathrm{~nm}(\bullet)\left(S_{1} \rightarrow\right.$ $\left.\mathrm{S}_{n}\right)$ and $750 \mathrm{~nm}(\boldsymbol{\Delta}) \mathrm{Anth}^{(-)}$.

scale of the TG experiment, we can conclude a high fraction of the initial ion pair population dissociates into free ions, with the latter decaying in the microsecond time scale by homogeneous recombination.

\section{Discussion}

By contrast to the previously reported ${ }^{6}$ syntheses of structurally similar compounds, our attempts to prepare the asymmetric $\mathrm{L}^{3}$ macrocycle by reductive alkylation of the model compound, $\mathrm{L}^{2}$, with 4-dimethylaminobenzaldehyde were unsuccessful. This effect, due to resonance stabilized deactivation of the carbonyl group by the electron donating dimethylamino substituent, necessitated an alternative synthetic procedure. Hence, solvent free 'melt' conditions were utilized to promote formation of the intermediate imine by loss of water at elevated temperatures, with subsequent reduction yielding the desired intermediate, 6-((4-dimethylaminobenzyl)amino)-trans-6,13-dimethyl-13-amino1,4,8,11-tetra-azacyclotetradecane, in sufficient quantity for use as the precursor of the secondary reductive alkylation. The desired compound was obtained in good yield and analytically pure form, as indicated by elemental analysis and ${ }^{1} \mathrm{H}$ NMR, allowing further facile isolation of X-ray quality crystals.

The structure of $\mathrm{L}^{3}$ is comparable to that previously observed $^{7,32}$ for other mono- and disubstituted derivatives of $\mathrm{L}^{1}$, although notably it is the first structurally characterized example of an asymmetrically disubstituted $\mathrm{L}^{1}$ analogue. As mentioned, primary motivation for the use of $\mathrm{L}^{1}$ as a linker between photoactive donor and acceptor components was the ease of functionalization at the pendant primary amines, leaving an essentially unmodified 'cyclam' core suitable for the coordination of various first row transition-metal cations. This goal has been realized, and the extensive intramolecular hydrogen 


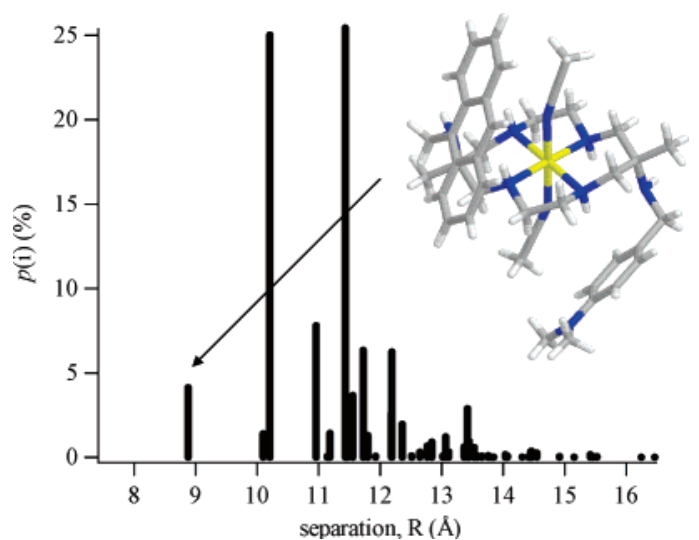

Figure 9. Modeled probability distribution as a function of interchromophore separation, $\mathrm{R}$, for $\left[\mathrm{ZnL}^{3}\left(\mathrm{CH}_{3} \mathrm{CN}\right)_{2}\right]^{2+}$ in the $\alpha$-trans-III $\mathrm{N}$-based isomeric form. Inset: Closest approach conformer (see text).

bonding pattern observed structurally for $\mathrm{L}^{3}$ provides a cavity ideally suited for binding transition-metal ions such as $\mathrm{Zn}(\mathrm{II})$.

Upon complexation, a single predominant isomer of $\left[\mathrm{ZnL}^{3}\right]^{2+}$ is formed in solution, as evidence from ${ }^{1} \mathrm{H}$ NMR titrations of the free ligand with a solution of $\mathrm{Zn}\left(\mathrm{ClO}_{4}\right)_{2} \cdot 6 \mathrm{H}_{2} \mathrm{O}$ (see Supporting Information, Figure S2). Sequential addition of $\mathrm{Zn}(\mathrm{II})$ resulted in a minor downfield shift of the methyl and linking methylene resonances, in accord with coordination of a divalent transition-metal ion within the macrocycle. Importantly, the linking methylene resonances appear as singlets indicating the pendant amine nitrogens are not coordinated to the metal and the aromatic groups are free to rotate. The identity of the major isomer is almost certainly the $\alpha$-trans-III N-based form (Figure 9), where the pendant amines adopt axial dispositions and the macrocyclic $\mathrm{NH}$ groups are able to $\mathrm{H}$-bond with these exocyclic amines. 9,33 Moreover, it is invariably this N-based isomer which has been observed crystallographically for many $\mathrm{Zn}$ (II) derivatives of cyclam (i.e. trans-III), ${ }^{34,35}$ the parent $\mathrm{L}^{1}$ macrocycle, ${ }^{36}$ and its functionalized derivatives. ${ }^{32,37}$

Absorption spectra for $\mathrm{L}^{3}$ and the corresponding $\mathrm{Zn}$ (II) complex were readily assigned to the parent chromophore, with the only notable difference being a slight bathochromic shift attributed to alkylation, as has been observed previously. ${ }^{38}$ Hence, the spectra of $\mathrm{L}^{3}$ and $\left[\mathrm{ZnL}^{3}\right]^{2+}$ comprise a simple superposition of transitions for the 9-anthracenylmethyl and 4-dimethylaminobenzyl (DMAB) chromophores. The absence of any new electronic transitions rules out any ground-state interaction between the $\pi$ electron systems of the two chromophores. After excitation, the emission spectrum of $\mathrm{L}^{3}$ was characteristically weak, which by analogy to the previously reported ${ }^{8,9}$ behavior of $\mathrm{L}^{2}$, may be attributed to a PET quenching reaction with amine lone pairs acting as electron donors. The occurrence of this deactivation pathway is further evident from the observation of an anthracene radical anion absorption using transient methods (Figures 6 and 8). Corresponding timeresolved measurements for $\mathrm{L}^{3}$ also revealed a multiexponential decay profile, with dynamic features spanning several orders of magnitude in time scale. Notably, for $\mathrm{L}^{3}$, the presence of the appended DMAB group provides an additional donor group compared to $\mathrm{L}^{2}$. The influence of the appended DMAB in quenching anthracene fluorescence is difficult to assess, given the competitive pathway utilising amine lone pairs as electron donors. Nevertheless, it is of interest that the average lifetime is significantly shorter for $\mathrm{L}^{3}$ than $\mathrm{L}^{2}$ (see Table 2).

Upon complexation with $\mathrm{Zn}(\mathrm{II})$, the decay kinetics of $\mathrm{L}^{3}$ are slowed considerably and become single exponential. This behavior may be easily rationalized as an effect of $\mathrm{Zn}$ (II) complexation, which protects the macrocyclic amine donors from photoinduced oxidation. Furthermore, it has been shown ${ }^{9}$ that for $\left[\mathrm{ZnL}^{2}\right]^{2+}$, the exocyclic amines are also deactivated toward PET quenching by $\mathrm{Zn}$ (II) complexation, most likely via an inductive effect of the proximal metal ion, and a similar situation should also hold for $\left[\mathrm{ZnL}^{3}\right]^{2+}$. Importantly, however, for $\left[\mathrm{ZnL}^{3}\right]^{2+}$, the appended DMAB group remains as a potential PET electron donor.

Thermodynamically, the PET reaction between the appended anthracene and DMAB moieties may be estimated using the general form of the Rehm-Weller equation ${ }^{39}$

$$
\Delta G^{\circ}(\mathrm{eV})=E^{\circ}\left(\mathrm{D}^{+} / \mathrm{D}\right)-E^{\circ}\left(\mathrm{A} / \mathrm{A}^{-}\right)-\Delta E_{00}
$$

where $E^{\circ}\left(\mathrm{D}^{+} / \mathrm{D}\right)$ is the standard redox potential for oxidation of the donor, $E^{\circ}\left(\mathrm{A} / \mathrm{A}^{-}\right)$is the standard redox potential for reduction of the acceptor, and $\Delta E_{00}$ is the spectroscopic zero point energy of the state for the photoactive component (in $\mathrm{eV}$ ) above the ground electronic state. In the present case, an analysis of this type was complicated by electrodeposition of elemental zinc on the electrode surface, which made it impossible to accurately determine the $\mathrm{An}^{0 /-}$ redox potential in the complex using cyclic voltammetry. Nonetheless, substituting the value obtained for the free ligand, the driving force for PET was estimated to be ca. $-0.43 \mathrm{eV}$, in agreement with similar calculations from the literature..$^{40}$

Transient grating results for $\left[\mathrm{ZnL}^{3}\right]^{2+}$, however, did not reveal any bands which could be assigned to anthracene radical anion formation by a PET reaction with the 4-dimethylaminobenzyl group acting as electron donor. This may be contrasted with the steady state and transient grating results from the intermolecular PET reaction (eq 3) of $\left[\mathrm{ZnL}^{2}\right]^{2+}$, where observation of a significant fluorescence quenching effect due to addition of $N, N$-dimethylaniline and the detectable anthracene radical anion spectrum were clearly evident (see Figures 5 and 8). Corresponding Stern-Volmer analysis of the steady-state data yielded an apparent $K_{\mathrm{sv}}$ of $39.9 \pm 0.99 \mathrm{M}^{-1}$, which, using the equation $^{39}$

$$
K_{\mathrm{sv}}=k_{\mathrm{q}} \tau_{\mathrm{o}}
$$

and a $\tau_{0}$ value of $2.21 \pm 0.05 \mathrm{~ns}$ as previously reported ${ }^{9}$ for the lifetime of $\left[\mathrm{ZnL}^{2}\right]^{2+}$ in $\mathrm{CH}_{3} \mathrm{CN}$ solution, corresponds to a quenching rate constant, $k_{\mathrm{q}}$, of $1.81 \pm 0.09 \times 10^{10} \mathrm{M}^{-1} \mathrm{~s}^{-1}$. The corresponding diffusional rate constant, $k_{\text {diff }}$, for $\mathrm{CH}_{3} \mathrm{CN}$ at $298 \mathrm{~K}$ is calculated to be $1.74 \times 10^{10} \mathrm{M}^{-1} \mathrm{~s}^{-1}$. Hence, the intermolecular PET quenching reaction shown in eq 3 may be considered to be diffusion limited.

The fluorescence decay curves collected for $\left[\mathrm{ZnL}^{3}\right]^{2+}$ in a $1: 1(\mathrm{v} / \mathrm{v}) \mathrm{CH}_{3} \mathrm{CN}$ :toluene solvent mixture yielded a lifetime of $4.1 \mathrm{~ns}$, which is comparable to that observed for $\left[\mathrm{ZnL}^{2}\right]^{2+}$ of $5.0 \mathrm{~ns}$ in the same solvent system. However, if the slightly diminished lifetime observed for $\left[\mathrm{ZnL}^{3}\right]^{2+}$ is taken as indirect evidence of a PET quenching effect, involving the appended DMAB moiety as an electron donor, and it is assumed the other deactivation pathways (eg. $k_{\mathrm{f}}, k_{\mathrm{ic}}, k_{\mathrm{isc}}$ ) are equivalent, a calculated PET rate constant, $k_{\mathrm{PET}}$, of $\sim 4.4 \times 10^{7} \mathrm{~s}^{-1}$ may be obtained using the relationship:

$$
\tau_{\mathrm{f}\left[\mathrm{ZnL}^{3}\right]^{2+}}=\frac{1}{\left(k_{\mathrm{f}}+k_{\mathrm{ic}}+k_{\mathrm{isc}}+k_{\mathrm{PET}}\right)}
$$

If present, however, this PET effect is clearly very weak, given the small differences observed in $\tau_{\mathrm{f}}$ between $\left[\mathrm{ZnL}^{2}\right]^{2+}$ and $\left[\mathrm{ZnL}^{3}\right]^{2+}$. 
Previous work, ${ }^{33}$ which utilized the parent $\mathrm{L}^{1}$ macrocycle as a bridge between appended naphthalene and anthracene chromophores to study intramolecular electronic energy transfer (EET), has ascribed the electronic coupling in that case primarily to a 'through space' Coulombic interaction, with a negligible 'through-bond' pathway. Since the macrocyclic linker is identical in this case, a similar situation will apply for the PET process under consideration here. In the absence of an effective 'throughbond' pathway, intramolecular PET must proceed via a 'throughspace' mechanism. To provide structural details of the separation between the 4-dimethylaminobenzyl electron donor and anthracene acceptor in the $\left[\mathrm{ZnL}^{3}\right]^{2+}$ complex, molecular modeling calculations were performed for the complex in the $\alpha$-trans-III $\mathrm{N}$-based isomeric form. Hence, for the 9-anthracenylmethyl chromophore oriented with an axial disposition, there exist 4 local minima, and, similarly, for the 4-dimethylaminobenzyl moiety, which has local $C_{2 v}$ symmetry, a total of 6 rotational minima are evident. In combination, a total of 48 combinations were modeled accounting for both 'syn' and 'anti' conformers. The resulting strain energy minimized structures were Boltzmann weighted to account for the flexibility of the appended chromophores using the equation ${ }^{41}$

$$
p(i)=\exp \left(\frac{-E_{i}}{k T}\right) / \sum_{i} \exp \left(\frac{-E_{i}}{k T}\right)
$$

where $E_{i}$ is the minimized strain energy of the $i$ th conformer, $k$ is the Boltzmann constant, and $T$ is the temperature $(298 \mathrm{~K})$. The resulting probability distribution of intramolecular separation, $R$, is shown in Figure 9. In this case, $R$ was defined as the distance between the aromatic carbon atom directly bound to the $\mathrm{Me}_{2} \mathrm{~N}-$ group of the 4-dimethylaminobenzyl moiety (approximately equivalent to the center of mass) and the center of the anthracene aromatic ring system. As shown in Figure 9, the majority of modeled conformers have intramolecular separations that are in excess of $10 \AA$, well in excess of the typical van der Waals radii for the donor and acceptor components. ${ }^{42}$ At this separation, the value of $k_{\mathrm{PET}}$ via a 'through-space' mechanism should be negligibly small, since the electron density of the donor and acceptor orbitals decreases exponentially with increasing radius. However, in a recent theoretical study of intermolecular PET between anthracene and dimethylaniline by Ando, ${ }^{40}$ PET rate constants were calculated as a function of the center of mass distance between the interacting donor acceptor pair and were found to rapidly increase with an apparent maximum of $\sim 10^{10} \mathrm{~s}^{-1}$ at a separation of ca. $5 \AA$. Moreover, the apparent separation yielding a rate constant of $\sim 10^{7} \mathrm{~s}^{-1}$ was ca. $8 \AA$, which is similar to the modeled 'closest approach' conformer shown in Figure 9. Thus, for the $\left[\mathrm{ZnL}^{3}\right]^{2+}$ complex, it is proposed that, while on the whole very inefficient, PET quenching of the anthracene excited state may occur when the fluorophore and electron donor are within sufficiently close proximity $(\sim 8-9 \AA)$ to allow a 'through-space' PET reaction. Unfortunately, other than the slightly diminished fluorescence lifetime, direct evidence for this process is lacking.

\section{Conclusions}

Experimental techniques required for the synthesis of asymmetrically disubstituted $\mathrm{L}^{1}$ derivatives are now well developed, and, with the structural characterization of $\mathrm{L}^{3}$ reported herein, the parent macrocycle has again proven itself amenable to further functionalization with a variety of differing functional groups. Unlike previous examples of this type, however, the anticipated enhancement of PET activity for $\left[\mathrm{ZnL}^{3}\right]^{2+}$ is notably absent.
Indeed, by comparison to the intermolecular behavior of $\left[\mathrm{ZnL}^{2}\right]^{2+}$ and DMA, PET activity is in fact diminished, no doubt due to the lack of an effective 'through-bond' electronic coupling pathway. Furthermore, it has become apparent the trans disposition of the pendant exocyclic amine attachment points and the bulk of the macrocyclic complex used as a bridge between the photoactive components inhibits their close approach in order to interact 'through-space'. Rather, the linker used or $\mathrm{L}^{3}$ can be envisaged as a 'molecular curtain' that screens the two groups and prevents their interaction. Hence, the importance of the bridge in influencing intramolecular PET dynamics and photophysical behavior has been illustrated.

Acknowledgment. E.G.M. gratefully acknowledges the award of a Graduate School Research Travel Award (GSRTA) from the University of Queensland and the Arlo D. Harris Travel Award from the Department of Chemistry.

Supporting Information Available: Crystallographic data for $\mathrm{L}^{3}$ in CIF format, ${ }^{1} \mathrm{H}$ NMR complexation of $\mathrm{L}^{3}$ with $\mathrm{Zn}(\mathrm{II})$, and ultrafast fluorescence decay profile and parameters for $\mathrm{L}^{3}$ measured by fluorescence upconversion. This material is available free of charge via the Internet at http://pubs.acs.org.

\section{References and Notes}

(1) Balzani, V.; Scandola, F. Supramolecular photochemistry; Ellis Horwood: New York, 1991

(2) Ide, R.; Sakata, Y.; Misumi, S.; Okada, T.; Mataga, N. J. Chem Soc., Chem. Commun. 1972, 1009.

(3) Okada, T.; Fujita, T.; Kubota, M.; Masaki, S.; Mataga, N.; Ide, R.; Sakata, Y.; Misumi, S. Chem. Phys. Lett. 1972, 14, 563.

(4) Mataga, N.; Nishikawa, S.; Asahi, T.; Okada, T. J. Phys. Chem. 1990, 94, 1443 .

(5) Wasielewski, M. R.; Minsek, D. W.; Niemczyk, M. P.; Svec, W. A.; Yang, N. C. C. J. Am. Chem. Soc. 1990, 112, 2823.

(6) Bruseghini, I.; Fabbrizzi, L.; Licchelli, M.; Taglietti, A. Chem. Commun. 2002, 1348

(7) Beer, P. D.; Bernhardt, P. V. J. Chem. Soc., Dalton Trans. 2001, 1428

(8) Bernhardt, P. V.; Flanagan, B. M.; Riley, M. J. J. Chem. Soc., Dalton Trans. 1999, 3579.

(9) Moore, E. G.; Bernhardt, P. V.; Fürstenberg, A.; Riley, M. J.; Smith, T. A.; Vauthey, E. J. Phys. Chem. A 2005, 109, 3788.

(10) Morandeira, A.; Engeli, L.; Vauthey, E. J. Phys. Chem. A 2002, 106,4833

(11) Hoegemann, C.; Pauchard, M.; Vauthey, E. Rev. Sci. Inst. 1996, 67,3449 .

(12) Vauthey, E. J. Phys. Chem. A 2001, 105, 340.

(13) Comba, P.; Hambley, T. W.; Lauer, G.; Okon, N. MOMEC 97, Version 2.1.3; University of Heidelberg, 1996.

(14) Bernhardt, P. V.; Comba, P. Inorg. Chem. 1992, 31, 2638.

(15) Sayle, R. A.; Bissell, R. A. Rasmol, Version 2.6; 1992. 374

(16) Sayle, R. A.; Milner-White, E. J. Trends Biochem. Sci. 1995, 20

(17) Farrugia, L. J. J. Appl. Crystallogr. 1999, 32, 8347.

(18) Sheldrick, G. M. Acta Crystallogr. A 1990, 46, 467.

(19) Sheldrick, G. M. SHELXL-97: Program for Crystal Structure Determination; University of Göttingen, 1997.

(20) Farrugia, L. J. J. Appl. Crystallogr. 1997, 30, 565.

(21) Mann, C. K.; Barnes, K. K. Electrochemical Reactions in Nonaqueous Systems; M. Dekker: New York, 1970.

(22) Friedel, R. A.; Orchan, M. Ultraviolet Spectra of Aromatic Compounds; Wiley: London, Chapman \& Hall: New York, 1951.

(23) Doub, L.; Vandenbelt, J. M. J. Am. Chem. Soc. 1947, 69, 2714.

(24) Oosterbaan, W. D.; van Gerven, P. C. M.; van Walree, C. A. Koeberg, M.; Piet, J. J.; Havenith, R. W. A.; Zwikker, J. W.; Jenneskens, L. W.; Gleiter, R. Eur. J. Org. Chem. 2003, 3117.

(25) Crosby, G. A.; Demas, J. N. J. Phys. Chem. 1971, 75, 991.

(26) Castanho, M. A. R. B.; Prieto, M. J. E. Biochim. Biophys. Acta 1998, 1373, 1

(27) Perrin, F. Compt. Rend. 1924, 178, 2252.

(28) Perrin, F. Compt. Rend. 1924, 178, 1978.

(29) Szczepanski, J.; Heldt, J. Z. Naturforsch. A 1985, 40A, 849.

(30) Goldschmidt, C. R.; Ottolenghi, M. Chem. Phys. Lett. 1970, 4, 570.

(31) Shida, T. Electronic Absorption Spectra of Radical Ions; Elsevier: Amsterdam, 1988. 
(32) Bernhardt, P. V.; Creevey, N. L. J. Chem. Soc., Dalton Trans. 2004, $6,914$.

(33) Moore, E. G.; Bernhardt, P. V.; Pigliucci, A.; Riley, M. J.; Vauthey, E. J. Phys. Chem. A 2003, 107, 8396.

(34) Alcock, N. W.; Berry, A.; Moore, P. Acta Crystallogr. C 1992, C48, 16 .

(35) Liang, X.; Weishaeupl, M.; Parkinson, J. A.; Parsons, S.; McGregor, P. A.; Sadler, P. J. Chem. Eur. J. 2003, 9, 4709.

(36) Bernhardt, P. V.; Lawrance, G. A.; Maeder, M.; Rossignoli, M.; Hambley, T. W. J. Chem. Soc., Dalton Trans. 1991, 1167.
(37) Bernhardt, P. V.; Moore, E. G.; Riley, M. J. Inorg. Chem. 2002, 41,3025 .

(38) Maiti, A. K. Chem. Phys. Lett. 1987, 134, 450.

(39) Kavarnos, G. J. Fundamentals of Photoinduced Electron Transfer; VCH: New York, 1993.

(40) Ando, K. J. Chem. Phys. 1994, 101, 2850.

(41) Schael, F.; Rubin, M. B.; Speiser, S. J. Photochem. Photobiol. A 1998, 115, 99.

(42) Bondi, A. J. Phys. Chem. 1964, 68, 441. 